EXTENDED REPORT

\title{
Longitudinal glaucoma screening for siblings of patients with primary open angle glaucoma: the Nottingham Family Glaucoma Screening Study
}

\author{
V C T Sung, J M Koppens, S A Vernon, P Pawson, M Rubinstein, A J King, C L Tattersall
}

Br J Ophthalmol 2006;90:59-63. doi: 10.1136/bjo.2005.072751

See end of article for authors' affiliations

Correspondence to: Mr Stephen A Vernon, DM, FRCS, FRCOphth, Eye, Ear, Nose and Throat Centre, Queen's Medical Centre University Hospital NHS Trust, Derby Road, Nottingham NG7 2UH UK; stephen.vernon@ qmc.nhs.uk

Accepted for publication 29 August 2005

\begin{abstract}
Aims: To assess the prevalence and cumulative incidence of open angle glaucoma (OAG) in a cohort group of siblings of OAG probands.

Methods: Between 1994 and 2003, a group of siblings of OAG probands underwent both initial and follow up standardised ophthalmic examinations. Siblings were classified as "definite glaucoma" (primary OAG (POAG) and normal tension glaucoma (NTG)), "glaucoma suspects" (NTG suspects or ocular hypertension (OHT)), and normal. The prevalence and cumulative incidence of OAG over the follow up interval were calculated.

Results: At the initial study, 271 siblings (mean age 63.6 years; female to male ratio 1.2) from 156 probands were examined. $32(11.8 \%)$ were classified as definite glaucoma and $15(5.5 \%)$ as suspects. In the follow up study, 157 of the 224 "normal" siblings from the initial study were examined (mean interval from initial study 7.0 (SD 1.0) years). 11 (7\%) were classified as definite glaucoma and 30 (19.1\%) as suspects. There were significant trends of increasing prevalence and incidence of OAG with age and a lifetime risk estimated at approximately $20 \%$ by age 70 .

Conclusion: Siblings of glaucoma patients have an increased risk of developing glaucoma and the risk increases with age. An effective and repeated screening programme should be considered for this high risk group.
\end{abstract}

$\mathrm{F}$ amily history is a known important risk factor for developing glaucoma. ${ }^{12}$ The Baltimore Eye Survey group reported a higher risk of glaucoma in siblings than in parents or children (odd ratios: 3.69, 2.17, and 1.12, respectively) of known glaucoma patients. ${ }^{3}$ The Barbados Eye Study Group also reported about four times increase in the risk of glaucoma in siblings of known glaucoma patients. ${ }^{4}$ However, many studies have relied on patient reporting of family history of glaucoma. Self reporting is subject to many biases, therefore, it is important to perform prospective studies on family members of glaucoma patients to assess the risk of glaucoma development in this population. Moreover, as increasing age is known to be a risk factor for glaucoma, the number of siblings with a diagnosis of glaucoma would be expected to increase with time. A pilot study from our group, screening siblings of glaucoma patients, reported in 1990 that $12.5 \%$ had glaucoma. ${ }^{5}$ A larger prospective study, "The Nottingham Family Glaucoma Screening Project (NFGSP)," commenced in 1994. The screening protocol was repeated in 2002 to screen those siblings who were negative for glaucoma at the first assessment. As far as we know, this is the first study to investigate longitudinally the prevalence and incidence of open angle glaucoma (OAG) in siblings of a cohort of patients with primary open angle glaucoma (POAG).

\section{METHODS}

In all, 212 white patients with typical high pressure POAG with no known family history of glaucoma who attended the glaucoma clinic between 1994 and 1997 acted as probands. All probands had pretreatment intraocular pressure (IOP) of $>21 \mathrm{~mm} \mathrm{Hg}$ and typical glaucomatous optic disc changes. The diagnoses of all probands were verified by a glaucoma specialist (SAV) and consent was obtained from the probands to contact their siblings. Siblings living within a 15 mile radius of the hospital were invited to attend for examination. Ethics approval was obtained from the ethics committee of Queen's Medical Centre University Hospital NHS Trust.

\section{Phase 1: first screening study}

Three hundred and thirty three siblings (of 188 probands) were invited to attend between 1994 and 1997. In those who attended, a full medical history was taken. The timing of their last optometric examination, if any, was also recorded. Then a full ophthalmological examination by a hospital based optometrist was undertaken, including visual acuity, automated perimetry with Humphrey 76 point suprathreshold program (Humphrey field analyser, Carl Zeiss Meditec Inc, Dublin, CA, USA). Slit lamp anterior segment biomicroscopy, anterior chamber depth assessment by Van Herrick method and IOP measurement with Goldmann type applanation tonometry were performed. Optic disc and fundus examinations were carried out with 78 dioptre lens (Volk Optical Inc, Mentor, USA) after pupil dilatation. A fellowship trained consultant ophthalmologist (SAV) then verified the findings with funduscopy. Abnormal field tests were defined as a cluster of two adjacent absolute defects or three adjacent relative defects excluding the edge testing points. A repeat perimetry with the Humphrey 24-2 Fastpac program was performed on subjects who failed the initial visual field test. Only field defects that were characteristic of glaucoma and could not be explained by other ocular pathology were classified as abnormal. ${ }^{6}$ The diagnoses were classified as in

Abbreviations: IOP, intraocular pressure; NTG, normal tension glaucoma; OAG, open angle glaucoma; $\mathrm{OHT}$, ocular hypertension; POAG, primary open angle glaucoma; VCDR, vertical cup to disc ratio 


\begin{tabular}{|c|c|c|}
\hline Classification & Diagnoses & Description \\
\hline $\begin{array}{l}\text { Definite } \\
\text { glaucoma }\end{array}$ & $\begin{array}{l}\text { Primary open angle } \\
\text { glaucoma } \\
\text { Normal tension glaucoma }\end{array}$ & $\begin{array}{l}1 \mathrm{OP}>21 \mathrm{~mm} \mathrm{Hg} \text {; glaucomatous optic disc changes with or without } \\
\text { visual field defect } \\
\text { IOP }<22 \mathrm{~mm} \mathrm{Hg} \text {; glaucomatous optic disc changes and } \\
\text { glaucomatous visual field defect }\end{array}$ \\
\hline $\begin{array}{l}\text { Glaucoma } \\
\text { suspect }\end{array}$ & $\begin{array}{l}\text { Ocular hypertension } \\
\text { Normal tension glaucoma } \\
\text { suspect }\end{array}$ & $\begin{array}{l}\text { IOP }>21 \mathrm{~mm} \mathrm{Hg} \text {; normal optic disc and visual field } \\
\text { IOP }<22 \mathrm{~mm} \mathrm{Hg} \text {; suspicious glaucomatous optic disc appearance } \\
\text { but normal visual field }\end{array}$ \\
\hline
\end{tabular}

table 1. Subjects classified as "glaucoma suspect" were referred to the glaucoma clinic for review.

\section{Phase II: second screening study}

In April 2002 to April 2003 (that is, 6-8 years after the initial study), siblings negative for glaucoma (including those originally defined as suspects) in the initial screening study were invited to attend a second screening examination. The general medical and ophthalmic histories were updated. A full ophthalmological examination was repeated and carried out by one of two experienced glaucoma fellows (VCTS and JMK) or a consultant ophthalmologist (AJK). Ophthalmological examinations and perimetry were carried out as in the initial protocol. In addition, central corneal thickness was measured with a contact ultrasound pachymeter (Tomey SP-2000, Tomey Corp, Cambridge, MA, USA). An abnormal perimetry result on the 76 point suprathreshold test was followed by a Humphrey C 24 SITA-Standard test on a separate occasion. The criteria for the classification of the diagnoses were the same as in the first screening study.

\section{Statistical analysis}

Comparison of baseline data between different diagnosis groups and "normals" were carried out by Kruskal-Wallis test with StatView for Windows, version 5 (SAS institute Inc, Cary, NC, USA). The prevalence and cumulative incidences for new cases of "definite glaucoma" and "at least glaucoma suspect" at first and second screening examinations, respectively, were assessed. The relative risks of baseline characteristics for the development of at least glaucoma suspect status were also calculated. ${ }^{7}$ Assessment of the trends of increasing age on prevalence and incidence of definite glaucoma were analysed with $\chi^{2}$ test for trend. ${ }^{8}$

\section{RESULTS}

Phase I: first screening study

Three hundred and thirty three siblings from 188 probands were invited to attend the screening study. Pre-visit telephone interview revealed that nine siblings from nine probands had already been diagnosed with glaucoma and were being treated. A further 51 rejected the offer of a screening examination and therefore a total of 273 siblings were seen.

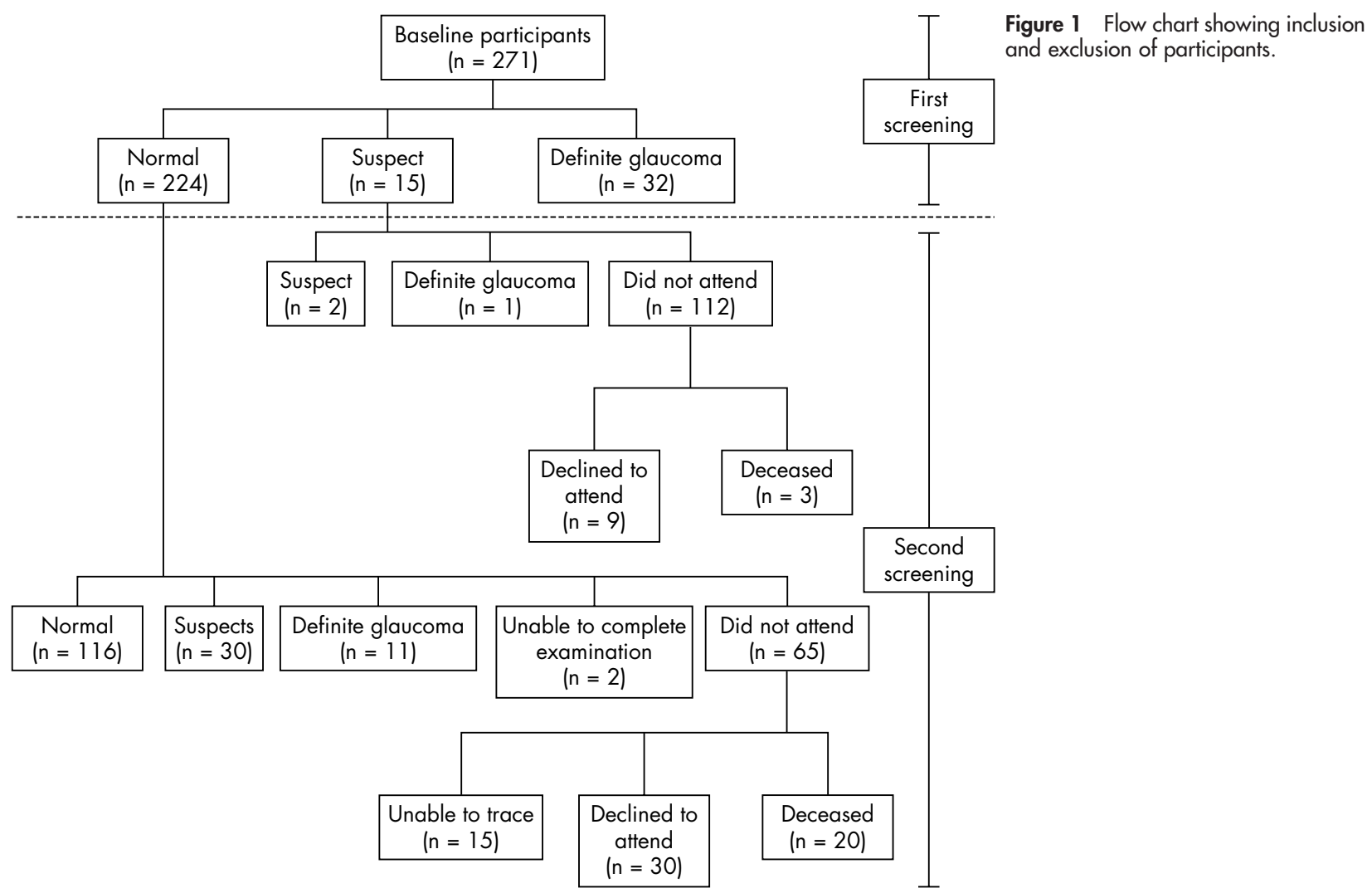


Table 2 Baseline patient characteristics in the three groups of patients at first screening study

\begin{tabular}{|c|c|c|c|c|c|}
\hline \multicolumn{2}{|l|}{ Patient characteristics } & Normal ( $n=224)$ & \multirow{2}{*}{$\begin{array}{l}\begin{array}{l}\text { Glaucoma } \\
\text { suspects }(n=15)\end{array} \\
61.93(10.67)\end{array}$} & $\begin{array}{l}\text { Definite } \\
\text { glaucoma ( } n=32)\end{array}$ & \multirow{2}{*}{$\frac{p \text { Value }}{0.003^{*}}$} \\
\hline Age & & $62.97(9.79)$ & & $69.06(6.88)$ & \\
\hline Sex F/M ratio & & 1.32 & 1.33 & 0.78 & NSt \\
\hline IOP: & RE & $15.09(2.80)$ & $17.19(4.92)$ & $18.41(4.55)$ & $0.0001^{*}$ \\
\hline & LE & $15.26(2.75)$ & $16.93(3.89)$ & $18.63(6.72)$ & $0.001^{*}$ \\
\hline Vertical cup disc ratio: & $\mathrm{RE}$ & $0.31(0.18)$ & $0.44(0.17)$ & $0.63(0.13)$ & $<0.0001^{*}$ \\
\hline & $\mathrm{LE}$ & $0.30(0.19)$ & $0.39(0.20)$ & $0.61(0.18)$ & $<0.0001^{*}$ \\
\hline
\end{tabular}

Table 3 Age specific prevalence of open angle glaucoma (first study)

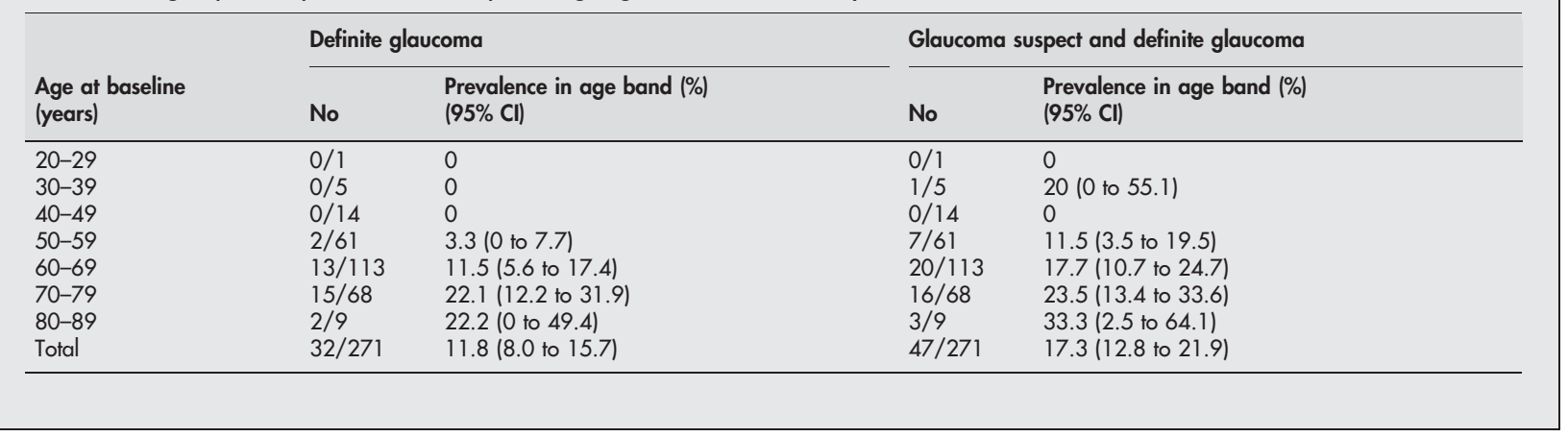

Following examination, a further two siblings were excluded because they were found to be half brothers of their respective probands. Therefore, data from 271 subjects of 156 probands were analysed (fig 1). The average age was 63.63 years and there were $150(55.4 \%)$ females and $121(44.6 \%)$ males.

Thirty two siblings $(11.8 \%)$ were classified as having definite glaucoma (17 (53\%) POAG and 15 (47\%) NTG), and $15(5.5 \%)$ were classified as glaucoma suspects (nine NTG suspects and six ocular hypertension (OHT)). Table 2 shows selected characteristics in all three groups. Table 3 shows the age specific prevalence of definite glaucoma and at least glaucoma suspect cases. The $\chi^{2}$ test for trend showed a significant trend of increasing prevalence with age in both definite glaucoma and at least glaucoma suspect cases ( $p$ $<0.001$ and $\mathrm{p}<0.02$ respectively).

The time between the last optometric examination and the study examination for those positive for glaucoma is shown in figure 2 (mean time 3.3 years, median 1.3 years). The mean time between probands' diagnosis of glaucoma and sibling screening for this group was 4.4 years.

\section{Phase II: second screening study}

Between April 2002 and February 2003, the 224 siblings classified as normal and 15 siblings classified as suspect from

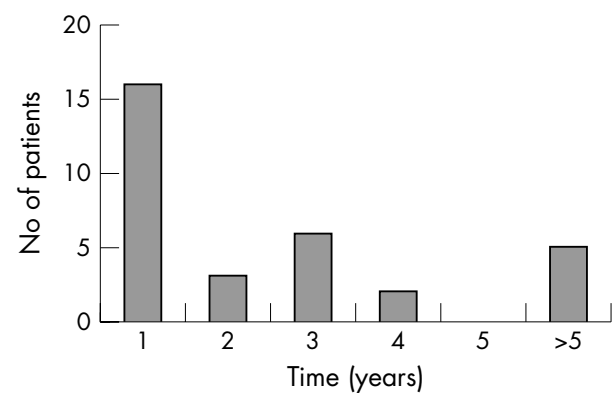

Figure 2 Histogram showing time between first screening visit and last community optometric visit in years to nearest year for those siblings diagnosed to have glaucoma at first screening visit $(n=32)$. the first screening study were invited to re-attend. Among the normal siblings, 20 subjects were dead, 15 subjects had either moved away from the area or could not be traced, and 30 subjects declined to attend. A total of 159 normal siblings therefore attended the second screening study. Two subjects were excluded; one as a result of dense cataract in both eyes precluding further meaningful assessment and one collapsed during the visual field test. This left 157 siblings of 106 probands (fig 1). The mean time between first and second screening examination was 7.0 (SD 1.0) years.

Eleven $(7 \%)$ were classified with definite glaucoma (six $(54.5 \%)$ POAG and five (45.5\%) NTG), with 30 (19.1\%) glaucoma suspects ( 12 NTG suspects and $18 \mathrm{OHT}$ ). Table 4 shows the age specific incidence of definite glaucoma and at least glaucoma suspect status. The $\chi^{2}$ test for trend showed a significant trend of increasing incidence with age in definite glaucoma and at least glaucoma suspect cases ( $p<0.02$ in both groups).

Only three of the 15 siblings classified as suspect from the first screening study attended the second screening study (fig 1). One (33.3\%) was then classified as definite glaucoma (NTG) and two as glaucoma suspects (two OHT). Three were dead; case note review was carried out on the remaining nine. One had been discharged to a community optometrist with low risk OHT. The remaining eight siblings (five NTG suspects and three OHT) had continued to attend the glaucoma clinic periodically and none had definite glaucoma at their last follow up visit. Since we are interested in the cumulative incidence (the number of new cases in a population which is disease free at baseline over a period of time), the results from this "suspects" group were not included in the incidence study.

The relative risk (RR) of baseline variables for the development of at least glaucoma suspect status in the first and second screening studies are presented in table 5. The effect of central corneal thickness measured by ultrasound pachymetry in the second screening study was assessed by taking the lower 25th centile of the average corneal thickness of a patient's two eyes as a cut-off level for risk $(<512 \mu \mathrm{m})$. 
Table 4 Age specific incidence of open angle glaucoma

\begin{tabular}{|c|c|c|c|c|}
\hline \multirow[b]{2}{*}{$\begin{array}{l}\text { Age at baseline } \\
\text { (years) }\end{array}$} & \multicolumn{2}{|c|}{ Definite glaucoma } & \multicolumn{2}{|c|}{ Glaucoma suspect and definite glaucoma } \\
\hline & No & $\begin{array}{l}\text { Incidence in age band (\%) } \\
(95 \% \mathrm{Cl})\end{array}$ & No & $\begin{array}{l}\text { Incidence in age band (\%) } \\
(95 \% \mathrm{CI})\end{array}$ \\
\hline $20-29$ & $0 / 1$ & 0 & $0 / 1$ & 0 \\
\hline $30-39$ & $0 / 4$ & 0 & $0 / 4$ & 0 \\
\hline $40-49$ & $0 / 10$ & 0 & $3 / 10$ & $30.0(1.6$ to 58.4$)$ \\
\hline $50-59$ & $1 / 36$ & $2.8(0$ to 8.1$)$ & $6 / 36$ & 16.7 (4.5 to 28.8$)$ \\
\hline $60-69$ & $4 / 75$ & $5.3(0.2$ to 10.4$)$ & $18 / 75$ & $24(14.3$ to 33.7$)$ \\
\hline 70-79 & $6 / 31$ & $19.4(5.4$ to 33.3$)$ & $14 / 31$ & $45.2(27.6$ to 62.7$)$ \\
\hline Total & $11 / 157$ & $7.0(3.0$ to 11.0$)$ & $41 / 157$ & 26.1 (19.2 to 33.0$)$ \\
\hline
\end{tabular}

As would be expected, IOP $>18 \mathrm{~mm} \mathrm{Hg}$, optic disc vertical cup to disc ratio (VCDR) $\geqslant 0.6$, and optic disc VCDR asymmetry $\geqslant 0.2$ were found to be significant risk factors for OAG in first screening study. However, none of the baseline variables from the first screening study were found to be a significant risk factor for the development of OAG in the second screening study.

\section{Lifetime risk of glaucoma}

In order to estimate the minimum lifetime risk of glaucoma in our population of siblings with a mean age at second screening of 69.2 years. This could be $16.0 \%([9+32+1+$ $11] / 331 \times 100 \%)$ for glaucoma if all those not attending the first study were negative and those suspects from the first screening who did not attend the second screening and the 30 suspects from the second screening remain nonglaucomatous for the rest of their lives. Assuming that a similar proportion of the siblings who did not attend were positive for glaucoma, then a lifetime risk of $19.3 \%([6.0+4.7$ $+9+32+1+11] / 331 \times 100 \%)$ is estimated at an age of about 70 years.

\section{DISCUSSION}

First degree relatives of known glaucoma patients have been identified to be the most at risk group to develop glaucoma, ${ }^{910}$ and of these, siblings have the highest risk. ${ }^{11}$ The Rotterdam study found the prevalence of glaucoma in first degree relatives to be $10.4 \%$ in siblings and $1.1 \%$ in offspring of patients. ${ }^{12}$ The Baltimore Eye Survey also found a higher risk of open angle glaucoma in siblings (9.9\%; odds ratio 3.69) than in parents (5.6\%; OR 2.17) and in children (1.2\%; OR 1.12). ${ }^{3}$ In the first phase of our study, we found the

Table 5 Univariate baseline risk factors for development of glaucoma or glaucoma suspect

\begin{tabular}{|c|c|c|c|c|}
\hline \multirow[b]{2}{*}{ Risk variables } & \multicolumn{2}{|c|}{ First screening } & \multicolumn{2}{|c|}{ Second screening } \\
\hline & $\begin{array}{l}\text { Relative } \\
\text { risk }\end{array}$ & $95 \% \mathrm{Cl}$ & $\begin{array}{l}\text { Relative } \\
\text { risk }\end{array}$ & $95 \% \mathrm{Cl}$ \\
\hline Male & 1.4 & 0.7 to 2.6 & 0.7 & $0.6,2.6$ \\
\hline Hypertension & 1.1 & 0.5 to 2.4 & 0.9 & 0.6 to 3.4 \\
\hline Diabetes (type 1 or 2 ) & 2.9 & 0.8 to 10.3 & 2.4 & 0.5 to 66.8 \\
\hline Migraine & 0.4 & 0.1 to 1.5 & 1.2 & 0.2 to 2.5 \\
\hline Raynaud's phenomenon & 0.6 & 0.2 to 1.7 & 0.9 & 0.6 to 4.2 \\
\hline Myopia $>-0.5$ dioptre & 1.3 & 0.6 to 2.9 & 1.0 & 0.2 to 1.7 \\
\hline $\mathrm{IOP}>18 \mathrm{~mm} \mathrm{Hg}$ & 6.2 & 3.1 to 12.3 & 1.0 & 0.9 to 6.3 \\
\hline $\begin{array}{l}\text { Optic disc VCDR } 0.6 \\
\text { or higher }\end{array}$ & 14.8 & 7.1 to 30.8 & 1.1 & 0.6 to 5.4 \\
\hline $\begin{array}{l}\text { Optic disc VCDR } \\
\text { asymmetry of } 0.2 \\
\text { or more }\end{array}$ & 3.5 & 1.6 to 7.6 & 1.3 & 0.5 to 7.4 \\
\hline $\begin{array}{l}\text { Central corneal } \\
\text { thickness }<512 \mu \mathrm{m}\end{array}$ & - & - & 0.8 & 0.9 to 4.1 \\
\hline
\end{tabular}

prevalence for OAG in our sibling group was $11.8 \%$ (95\% CI $=8.0 \%, 15.7 \%$ ) similar to the aforementioned two studies, but lower than the Barbados Family Study which found $19.8 \%(67 / 338)$ of siblings to have OAG in a population mainly comprising Afro-Caribbeans. ${ }^{13}$ This is also reflected by the higher prevalence of OAG in a predominantly black population $(7 \%)^{14}$ compared to $1.1 \%$ to $3 \%$ in predominately white population. ${ }^{15-19}$ Comparing our study with large population epidemiological studies, our study has a more stringent diagnostic criteria for the probands, which may reduce the risk of possible misclassification.

The higher prevalence of OAG in siblings of glaucoma probands is likely to be because of the closer genetic make-up and perhaps a similar environment during childhood. A recent segregation analyses of the data from the Barbados Family Study showed the transmission of OAG and probable OAG is likely to be the result of a major co-dominant gene, with age as a significant risk factor for developing OAG. ${ }^{20}$ Therefore, it is important to ascertain the incidence of OAG in a group of siblings who were negative for OAG in the first screening study. As far as we know, there has been no previous study on long term incidence of OAG in a cohort group of siblings of OAG patients.

Previous incidence studies of OAG in mainly white populations have shown similar results. The Swedish 10 year study of manifest glaucoma showed a cumulative incidence of $2.4 \%$ (about $0.24 \%$ per year). ${ }^{21}$ The Melbourne Visual Impairment project showed the 5 year incidence of definite OAG to be $0.5 \%$ (about $0.1 \%$ per year) and the overall incidence of definite, probable and possible OAG as $2.7 \%$ (0.55\% per year). ${ }^{22}$ The Barbados Eye Study reported a 4 year incidence of definite OAG of $2.2 \%$ (about $0.6 \%$ per year). ${ }^{23}$ In our study, all the families involved in the study were European white people with a cumulative incidence of definite OAG over an average of 7 years between the study phases being $7.0 \%(95 \%$ CI $=3.0 \%$ to $11.0 \%)$, and the cumulative incidence of "at least glaucoma suspect" at $26.1 \%$ $(95 \%$ CI $=19.2 \%$ to $33.0 \%)$ - that is, approximately $1 \%$ and $3.7 \%$ per year, respectively. This much higher incidence of OAG in our study is most likely because of the positive family history in our siblings. Interestingly, the incidence in this study is much higher than the Bedford Survey conducted in the 1980s on 101 individuals with a positive family history of glaucoma. They reported a 3\% incidence of definite glaucoma after 10-12 years of follow up. ${ }^{2}$ It is of note that only 17 of their subjects were siblings and the others were mostly children of probands and by necessity of much younger age.

Another interesting observation in our study is the high prevalence and incidence of normal tension glaucoma $(47 \%$ and $46 \%$, respectively) in our sibling group, even though all the probands had "classic" high pressure OAG. Apart from the increased risk of raised IOP in subjects with a family history of glaucoma, the inherited vulnerability of the optic disc to IOP may also increase in family members. A recent study 
by Klein et al showed the optic disc morphological features correlate well between gene related family members. ${ }^{24}$

Both prevalence and incidence of OAG have been found to increase with age. 22232526 In our study, we found both prevalence and incidence of OAG increased with age in siblings. Unlike other studies, ${ }^{22}{ }^{23}$ we did not find a sex difference in the incidence of glaucoma. Higher IOP, larger optic disc VCDR and disc cupping asymmetry were found to be significant risk factors for the presence of OAG in the first phase. However, the presence of these risk factors at baseline did not increase the risk of developing OAG in the second phase. This suggests that IOP elevation and a change in optic disc morphology occurred during the follow up period in those who converted. We therefore could not predict which siblings were more likely to develop glaucoma from a baseline examination, indicating that continued regular examination is necessary for all siblings.

In this study, we have confirmed that siblings of white patients with OAG have a high prevalence of OAG compared to the general population and they also have an increased incidence rate once they achieve the age of 60 . It is of note that the median time between the first study examination and the last visit to a community optometrist is just over 1 year indicating that, at least in the mid-1990s, the sensitivity of glaucoma detection by optometrists was less than optimal for a high risk group. We therefore suggest that formal screening resources should be targeted at this high risk group and that a screening programme should actively recall siblings every 2 years even if the initial screening results are negative.

\section{ACKNOWLEDGEMENTS}

The authors thank the study participants, Mrs Alison Adair (Department of Ophthalmology, Queen's Medical Centre, Nottingham) for her assistance in the whole period of this study, and Miss Chih-Mei Chen (Trent Institute for Health Services Research, Nottingham) for her advice on statistical analysis. The first study was supported in part by a grant from Nottingham District Health Authority and the Humphrey analyser was loaned by Humphrey Zeiss Instruments.

\section{Authors' affiliations}

V C T Sung, J M Koppens, S A Vernon, P Pawson, M Rubinstein, A J King, C L Tattersall, Eye, Ear, Nose and Throat Centre, Queen's Medical Centre University Hospital NHS Trust, Derby Road, Nottingham NG7 2UH, UK

V C T Sung, Birmingham and Midland Eye Centre, Sandwell and West Birmingham Hospital NHS Trust, Dudley Road, Birmingham B18 7QU, UK

The authors have no competing interest in the instruments used in this study.

\section{REFERENCES}

1 Miller SJ. Genetics of glaucoma and family studies. Trans Ophthalmol Soc UK 1978;98:290-2.

2 Rosenthal AR, Perkins ES. Family studies in glaucoma. Br J Ophthalmol 1985:69:664-7.

3 Tielsch JM, Katz J, Sommer A, et al. Family history and risk of primary open angle glaucoma. The Baltimore Eye Survey. Arch Ophthalmol 1994;112:69-73.

4 Nemesure B, Leske MC, $\mathrm{He} Q$, et al. Analyses of reported family history of glaucoma: a preliminary investigation. The Barbados Eye Study Group. Ophthalmic Epidemiol 1996;3:135-41.

5 Vernon SA. Screening siblings for glaucoma in the UK. J R Soc Med 1991;84:545-6.

6 Katz J, Tielsch JM, Quigley HA, et al. Automated perimetry detects visual field loss before manual Goldmann perimetry. Ophthalmology 1995;102:21-6.

7 Hennekens CH, Buring JE. Measures of disease frequency. In: Mayrent SL, ed. Epidemiology in medicine. Philadephia: Lippincott Williams \& Wilkins, 1987:54-96.

8 Altman D. Practical statistics for medical research. 1st ed. London: Chapman and Hall, 1991:344-5.

9 Perkins ES. Family studies in glaucoma. Br J Ophthalmol 1974;58:529-35.

10 Leighton DA. Survey of the first-degree relatives of glaucoma patients. Trans Ophthalmol Soc UK 1976;96:28-32.

11 Nguyen RL, Raja SC, Traboulsi El. Screening relatives of patients with familial chronic open angle glaucoma. Ophthalmology 2000;107:1294-7.

12 Wolfs RC, Klaver CC, Ramrattan RS, et al. Genetic risk of primary open-angle glaucoma. Population-based familial aggregation study. Arch Ophthalmol 1998;116:1640-5.

13 Leske MC, Nemesure B, $\mathrm{He} Q$, et al. Patterns of open-angle glaucoma in the Barbados Family Study. Ophthalmology 2001;108:1015-22.

14 Leske MC, Connell AM, Schachat AP, et al. The Barbados Eye Study. Prevalence of open angle glaucoma. Arch Ophthalmol 1994;112:821-9.

15 Tielsch JM, Sommer A, Katz J, et al. Racial variations in the prevalence of primary open-angle glaucoma. The Baltimore Eye Survey [see comments]. Jama 1991; 266:369-74.

16 Klein BE, Klein R, Sponsel WE, et al. Prevalence of glaucoma. The Beaver Dam Eye Study. Ophthalmology 1992;99:1499-504.

17 Coffey M, Reidy A, Wormald R, et al. Prevalence of glaucoma in the west of Ireland. Br J Ophthalmol 1993;77:17-21.

18 Mitchell P, Smith W, Attebo K, et al. Prevalence of open-angle glaucoma in Australia. The Blue Mountains Eye Study. Ophthalmology 1996;103:1661-9.

19 Dielemans I, Vingerling JR, Wolfs RC, et al. The prevalence of primary openangle glaucoma in a population-based study in the Netherlands. The Rotterdam Study. Ophthalmology 1994;101:1851-5.

20 Nemesure $B, \mathrm{He} Q$, Mendell $N$, et al. Inheritance of open-angle glaucoma in the Barbados family study. Am J Med Genet 2001;103:36-43.

21 Bengtsson BO. Incidence of manifest glaucoma. Br J Ophthalmol 1989:73:483-7.

22 Mukesh BN, McCarty CA, Rait JL, et al. Five-year incidence of open-angle glaucoma: the visual Impairment Project. Ophthalmology 2002; 109:1047-51

23 Leske MC, Connell AM, Wu SY, et al. Incidence of open-angle glaucoma: the Barbados Eye Studies. The Barbados Eye Studies Group. Arch Ophthalmol 2001;119:89-95.

24 Klein BE, Klein R, Lee KE. Heritability of risk factors for primary open-angle glaucoma: the Beaver Dam Eye Study. Invest Ophthalmol Vis Sci 2004:45:59-62.

25 Weisschuh N, Schiefer U. Progress in the genetics of glaucoma. Dev Ophthalmol 2003;37:83-93.

26 Le A, Mukesh BN, McCarty CA, et al. Risk factors associated with the incidence of open-angle glaucoma: the visual impairment project. Invest Ophthalmol Vis Sci 2003;44:3783-9. 